\title{
A Clínica Psicanalítica com Adolescentes: Especificidades de um Encontro Analítico
}

The Psychoanalytical Clinic With Adolescents:

Specificities Of An Analytical Encounter

La Clínica Psicoanalítica Con Adolescentes:

Especificidades De Un Encuentro Analítico

Renata Cardoso Plácido Ayub \& Mônica Medeiros Kother Macedo

Pontifícia Universidade Católica do Rio Grande do Sul
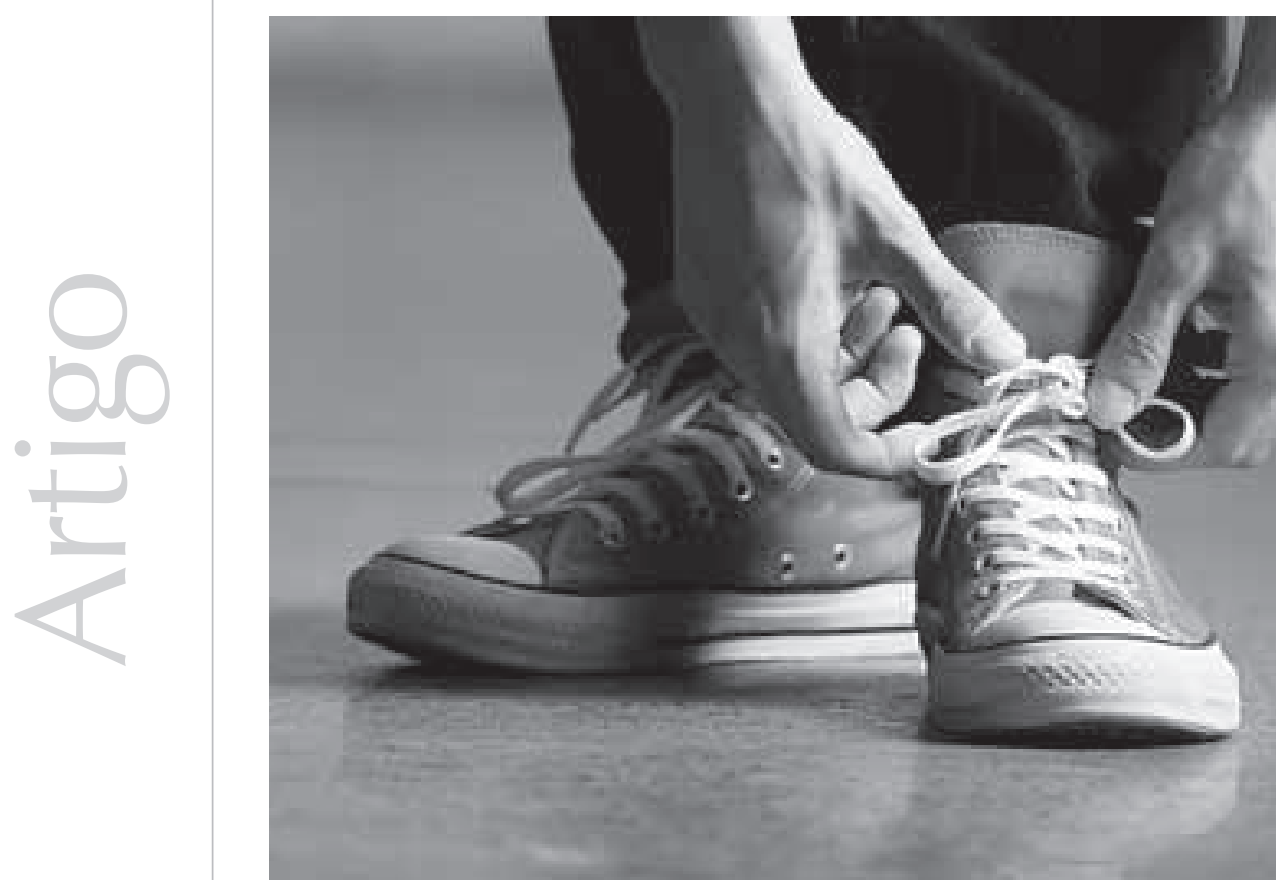
Resumo: As contínuas transformações experienciadas pelos adolescentes têm sido objeto de estudo em função da importância que adquirem no contexto da saúde psíquica. Este artigo retrata um estudo de cunho qualitativo, que objetivou conhecer e compreender as características e as peculiaridades da clínica contemporânea da adolescência considerando o exercício da escuta psicanalítica. Foram entrevistados dez psicanalistas com atuação de, no mínimo, dez anos no atendimento a pacientes dessa faixa etária. Por meio da técnica de análise de conteúdo, foram identificadas três categorias finais: a família e a escola como campos fundamentais da experiência intersubjetiva do adolescente, a necessidade de recursos psíquicos: exigências para o enfrentamento do processo de ressignificação de si mesmo, e, por último, os desafios e as inquietações no campo analítico: especificidades teóricas e técnicas a partir da escuta de adolescentes. Para a discussão dos achados, lançou-se mão do referencial psicanalítico. O estudo realizado permitiu não só conhecer melhor a articulação das demandas da cultura atual com as modalidades psicopatológicas presentes na clínica psicanalítica da adolescência assim como identificar as transformações que ocorrem na técnica psicanalítica. O espaço da análise evidenciou-se como uma relevante possibilidade de construção e de atribuição de significado aos padecimentos psíquicos da adolescência, de modo a viabilizar desdobramentos saudáveis às suas vivências.

Palavras-chave: Adolescência. Psicanálise. Psicologia clínica. Intervenção psicológica.

Abstract: The continuous transformations adolescents experience have been object of study because of its importance in the context of psychic health. This paper portrays a qualitative study that aimed to know and to comprehend the characteristics and peculiarities of the contemporary adolescence clinic, considering the practice of the psychoanalytical listening. Ten psychoanalysts who had been at least ten years attending adolescents patients were interviewed. Through the technique of content analysis, three final categories were identified: the family and the school as fundamental fields of the inter-subjective experience of the adolescent, the necessity of psychic resources: demands to cope with the re-signification of oneself, and, finally, the challenges and concerns in the analytical field: theoretical and technical specificities from the adolescence's listening. For the discussion of the findings, it was used the psychoanalytical referential. The study accomplished allowed a better knowledge about the articulations of the current culture demands with the pathological modalities present in the adolescent's psychoanalytical clinic, as well as identify the transformations that occur in the psychoanalytical technique. The analysis has been highlighted as a relevant possibility to construct and assign meanings to the psychic suffering of adolescents in order to provide healthy developments for their experiences.

Keywords: Adolescence. Psychoanalysis. Clinical psychology. Psychological intervention.

Resumen: las continuadas transformaciones experimentadas por los adolescentes han sido objeto de estudio en función de la importancia que adquieren en el contexto de la salud psíquica. Este artículo retracta un estudio de naturaleza cualitativa, que ha tenido como objetivo conocer y comprender características y peculiaridades de la clínica contemporánea de la adolescencia, considerando el ejercicio de la escucha psicoanalítica. Han sido entrevistados diez psicoanalistas, con una actuación de por lo menos diez años en la atención a pacientes adolescentes. A través de la técnica de Análisis de Contenido, se han identificado tres categorías finales: la familia y la escuela como campos fundamentales de la experiencia intersubjetiva del adolescente; la necesidad de recursos psíquicos: exigencias para el enfrentamiento del proceso de resignificación del sí mismo; y, por último, desafíos e inquietudes en el campo analítico: especificidades teóricas y técnicas a partir de la escucha de adolescentes. Para la discusión de los resultados encontrados, se ha llevado a cabo el referencial psicoanalítico. El estudio llevado a cabo ha permitido un mejor conocimiento acerca de la articulación de las demandas de la cultura actual con las modalidades psicopatológicas presentes en la clínica psicoanalítica de la adolescencia, así como identificar transformaciones que ocurren en la técnica psicoanalítica. El espacio del análisis se ha evidenciado como una relevante posibilidad de construcción y atribución de significado a los padecimientos psíquicos de la adolescencia, de forma a tornar viables despliegues saludables a sus vivencias.

Palabras clave: Adolescencia. Psicoanálisis. Psicología clínica. Intervención psicológica.

A adolescência é uma etapa da vida marcada por complexas demandas que resultam em inegável exigência de investimentos por parte do sujeito. Os fatores biológicos, considerados intrínsecos da puberdade, designam as mudanças corporais e fisiológicas, enquanto as demandas psíquicas compreendem um intenso trabalho de metabolização de transformações psicossociais que estão mais especificamente associadas ao termo adolescência (Levisky, 1995; Blos, 1998; Macedo, Fensterseifer, \& Werlang, 2004). Tais 
processos biológicos e psicossociais, ainda que estejam mutuamente implicados e possam ocorrer simultaneamente durante esse período, são compreendidos como eventos distintos devido a suas especificidades.

Na adolescência, ocorrerá um trabalho de ressignificação da identidade, possibilitando o acesso do jovem a outra etapa do ciclo vital. A sociedade oferece, de acordo com a sua cultura, rituais tradicionais de passagem à idade adulta que funcionam como mediações simbólicas entre o adolescente e o meio, e que lhe conferirão o status de adulto.

$\mathrm{Na}$ atualidade, observa-se, como efeito das transformações sociais e culturais, uma redução do período historicamente caracterizado como infância e a decorrente expansão da adolescência. Nessa linha de raciocínio, Birman (2006) considera que a contemporaneidade vive tempos de uma adultez com critérios indefinidos, fato que dificulta demarcações, em termos de subjetividade, das idades da vida. O autor afirma que isso provoca, em consequência, uma desordem no contexto familiar, na qual a relação com o aspecto dos cuidados é significativamente afetada, refletindose nas novas formas de subjetivação da adolescência. O tema do cuidado remete a uma assimetria necessária entre a criança e o adulto, a partir da qual se constroem condições para uma progressiva autonomia no campo intersubjetivo.

Por vezes, as demandas que adentram a clínica psicanalítica podem se originar de uma necessidade do adolescente ou terem como origem uma necessidade do contexto social principal (família e escola), expressando alguma preocupação/queixa a respeito do adolescente. É comum que algumas manifestações da adolescência sejam recebidas com desconforto, necessitando, por vezes, da atribuição de um rótulo que normatize e padronize tais manifestações.
Há casos que ocorrem com adolescentes que dizem respeito a manifestações de conflitos referentes à temática da diferença, do rompimento, das transformações que, inclusive, podem representar sua saída para a saúde, daí a importância da escuta do aspecto inegável de singularidade presente em cada padecimento humano, independentemente da idade em que ocorra.

Considerando-se, portanto, que os motivos de busca de um tratamento possam variar, sabe-se que a vivência da escuta do paciente, seja via palavra, seja via conduta, possibilita uma atribuição única de sentido às suas dores. A psicanálise, diante da singularidade de cada sujeito, coloca-se como um importante recurso para compreensão e intervenção nos padecimentos psíquicos. É possível, com base em um ponto de vista que enfatiza a complexidade inerente ao ser humano, articular as modalidades de sofrimento da adolescência com as transformações impostas pela contemporaneidade. Mais do que criar categorias de padecimentos, busca-se a interrogação dos efeitos dessas transformações especificamente na adolescência. O que se pode esperar da psicanálise nos tempos atuais é, segundo Dockhorn e Macedo, "a construção de um espaço onde o intrapsíquico seja priorizado, a singularidade respeitada, e a implicação do sujeito em seu padecimento possa ser escutada" (2008, p.14) Segundo as autoras, busca-se, dessa forma, possibilitar trocas intersubjetivas mais ricas e menos fugazes, constituindo-se um espaço onde o desejo possa ser reconhecido e, portanto, onde o sujeito se reconheça como ser desejante. $\mathrm{O}$ analista, nesse espaço de intersubjetividade, oferece ao paciente recursos de acesso a novas e singulares atribuições de sentido para a sua história. No cruzamento das temáticas adolescência e psicanálise, cabe questionar como se presentificam, na contemporaneidade, as demandas adolescentes para a escuta psicanalítica. 
Kupermann (2007) destaca que esta impõe ao analista constantes desafios ao longo de todo o tratamento. No início, por exemplo, o principal desafio reside na (im) precisão da indicação do tratamento, a partir de uma queixa do adolescente ou de seu contexto social.
Em seu artigo sobre a análise de adolescentes, Kupermann (2007) destaca que esta impõe ao analista constantes desafios ao longo de todo o tratamento. No início, por exemplo, o principal desafio reside na (im)precisão da indicação do tratamento, a partir de uma queixa do adolescente ou de seu contexto social. Há que se avaliar, por meio da escuta analítica, se se trata de um padecimento psíquico, típico ou não, no qual o adolescente se beneficiaria com o processo de análise. Dessas dificuldades decorrem interrogações teóricas e técnicas dos analistas que se encontram, em uma dimensão ética, atreladas à responsabilidade com a manutenção de uma prática atualizada (formação) e com a efetividade do tratamento. Logo, é relevante uma compreensão aprofundada dos efeitos socioculturais no processo de subjetivação do adolescente. Considerando a importância desse momento do ciclo vital, sua inegável relação com fatores sociais e culturais, assim como a demanda intensa de trabalho psíquico que a psicanálise enfatiza ao se referir à temática adolescente, este estudo buscou conhecer e explorar as demandas, características e peculiaridades da clínica contemporânea da adolescência. $\mathrm{Na}$ medida em que a escuta se apresenta como ferramenta clínica essencial no exercício da psicanálise, tomou-se como ponto de partida a experiência de analistas no atendimento clínico de adolescentes.

\section{Método}

Participaram deste estudo dez psicanalistas, localizados por conveniência, independentemente de instituição formadora, com experiência de um período mínimo de 10 anos de prática clínica no atendimento de pacientes adolescentes. Três participantes são do sexo masculino, e sete são do sexo feminino, sendo, do total, quatro médicos psiquiatras e seis psicólogos.

Após aprovação do projeto de pesquisa pelo Comitê de Ética da Universidade, os participantes foram contatados por indicação de seus pares; todos assinaram o Termo de Consentimento Livre e Esclarecido (TCLE) e participaram de uma entrevista semiestruturada de questões abertas, na qual foram contemplados os seguintes tópicos: particularidades que levam um adolescente a buscar atendimento psicanalítico, demandas e configurações de padecimentos psíquicos apresentadas por adolescentes em relação ao contexto contemporâneo, relação entre adolescência e sofrimento psíquico e interrogações teóricas e técnicas citadas pelos psicanalistas oriundas da escuta psicanalítica da clínica com adolescentes. As entrevistas foram gravadas em áudio e transcritas para garantir a fidedignidade dos dados. Após a transcrição, foram identificadas, a partir das verbalizações dos participantes, categorias de análise, cujos dados foram analisados através da técnica de análise de conteúdo, de Bardin (1988).

\section{Resultados e discussão}

A idade média dos participantes deste estudo é de 50,5 anos. A média de tempo de graduação é de 24 anos, e a de tempo de atendimento na clínica psicanalítica, de 22,1 anos; todos os participantes têm experiência na clínica de adolescentes de, no mínimo, dez anos.

A descrição de cada categoria final (ver Tabela) foi estruturada a partir das categorias intermediárias que lhe deram origem e, com a finalidade de proporcionar rigor e validade às categorias, foram transcritas, de forma fiel, algumas verbalizações dos participantes entrevistados. 


\section{Tabela de Categorias}

Categorias Iniciais
Novas configurações familiares como possibilidades de
novos modelos de referência para o adolescente

Novas configurações familiares como desafio a capacidade de flexibilização do adolescente

Relações familiares: cenário de experiências de amparo e desamparo frente às exigências do processo adolescente
Novas configurações familiares dificultando o estabelecimento de limites estruturantes para o adolescente

Confusão na delimitação de papéis na família Família identificando preocupações e encaminhando o adolescente para tratamento

Imposições de ideais no contexto familiar

A escola como palco para a expressão das dificuldades do adolescente

A escola como possibilidade de detectar 'problemas' na adolescência

Adolescente çomo caixa de ressonância dos processos culturais atuais

Angústia generalizada

Angústia no corpo

Problemáticas relacionadas à alteridade

Sofrimentos típicos da adolescência

Cultura como incremento da descarga em ato

Cultura do imediatismo

Efeitos da violência na contemporaneidade

Internet como possibilidade irrestrita de informações

Internet empobrecendo os vínculos

Vínculos e expressões narcisistas da cultura atual

História inicial de desamparo

Apatia

Desmotivação/desinteresse

Descargas no corpo como alternativa frente às experiências do processo de subjetivação

Uso de drogas como alternativa frente às experiências do processo de subjetivação

Modelo de sociedade imediatista contribuindo para dificuldades no enquadre

Leitura não linear do padecimento psíquico adolescente

Benefícios do tratamento

Desafios do trabalho analítico

Interrogantes sobre o sintoma adolescente

Impasses na técnica

Especificidades da técnica com adolescentes

Estabelecimento do vínculo como base para o tratamento do adolescente

Recursos teóricos para o atendimento das demandas atuais
O espaço da escola para a

expressão de dor psíquica

Efeitos dos enlaces e desenlaces entre as demandas externas e recursos intrapsíquicos

Influências da cultura nas formas de expressão de padecimento psíquico do adolescente
Categorias Finais

A família e a escola como campos fundamentais da experiência intersubjetiva do adolescente
Necessidade de recursos psíquicos: exigências para o enfrentamento do processo de ressignificação do si mesmo
Passividade como característica dominante no campo intersubjetivo frente ao empobrecimento do si mesmo

Padecimentos/Patologias do Ato como descarga de intensidades
Transformações necessárias no espaço clínico (teoria/técnica)
Desafios e inquietações no campo analítico: especificidades teóricas e técnicas a partir da escuta de adolescentes
Complexidade dos padecimentos psíquicos adolescentes 
A primeira categoria final foi denominada a família e a escola como campos fundamentais da_experiência intersubjetiva do adolescente. A adolescência contempla um espaço de interrogações e incertezas a respeito de si mesmo e de suas relações com o semelhante. A família é o espaço que inaugura a experiência intersubjetiva de um indivíduo. Nessa perspectiva, os entrevistados se referem, a partir de sua escuta na clínica, a uma grande preocupação acerca da fragilidade psíquica que se faz presente desde a chegada de adolescentes no espaço da clínica:

É um psiquismo que já vem mal estruturado; como é que ele vai se apresentar nessa faixa etária, com tantas mudanças físicas, psíquicas e juntando a isso mais a exigência de uma sociedade, o momento atual que a gente está vivendo? (...) Ele se vê muito exigido e não tem estrutura para isso. Então como é que ele vai reagir? Quais são as defesas que vai lançar? (P1).

É possível refletir sobre um aspecto dessa fragilidade a partir de considerações sobre o processo de estruturação do psiquismo. A respeito da constituição do eu, Hornstein (1989) afirma que o sujeito há que ser adequadamente narcisizado pelos pais. Esse processo de narcisização se refere ao encontro no campo intersubjetivo que compreende, por parte das figuras significativas na vida da criança, uma experiência com os enunciados de um outro a respeito do eu incipiente (Hornstein, 1989). A criança, ao se identificar com aquilo que é enunciado pelo outro, inaugura seu espaço próprio de subjetividade. Lerner (2007) assinala que o marco e a condição para a produção de subjetividade de um sujeito se dão pelo intercâmbio social. O meio configura um campo de expectativas às figuras parentais que resultam na produção de expectativas por parte da criança. A qualidade dos investimentos parentais é, portanto, muito importante no que diz respeito ao processo de estruturação do eu e, também, no estabelecimento de condições para vir a ser e estar no mundo.

Hornstein (1989) destaca que, para se refletir acerca da estruturação da subjetividade, faz-se necessário um enlace com as proposições a respeito da conflitiva edípica, uma vez que todo o desenvolvimento humano está atravessado por aspectos relacionados ao nascimento, à separação (como individualizante), à triangulação edípica, à latência, à eleição de objeto e à adolescência. Constata-se que a vivência edípica trará importantes transformações ao narcisismo, ou seja, a experiência edípica produz efeitos relevantes no Eu. Segundo o autor, a saída desse circuito culminaria, sumariamente, no deslocamento libidinal para objetos exogâmicos. Assim, é a partir da elaboração de uma série de diferenças, desde a relação da mãe e do bebê, passando pelo enfrentamento das diferenças entre as figuras parentais, entre os sexos e entre os espaços endogâmico e exogâmico, que o psiquismo reorganiza a representação de sua referência com o mundo (Hornstein, 1989).

Um ponto essencial da adolescência diz respeito à reedição da conflitiva edípica, aspecto psíquico que marca de forma indelével esse momento da vida. Sendo a adolescência um tempo de importantes ressignificações, frente à reedição dessa temática, faz-se necessário que o adolescente renuncie aos objetos iniciais de amor e, a partir de desidealizações, encontre novos modelos de identificação que lhe possibilitem adquirir maior autonomia e maturidade em suas escolhas. A intensidade com a qual retorna a questão edipiana na adolescência associa-se, segundo Pinheiro (2001), ao fato de o objeto a ser abandonado, agora em favor de novos investimentos, ser o mesmo que o narcisizou inicialmente, ou seja, é aquele objeto por meio do qual o adolescente, na infância, acreditava ter garantias de amor incondicional, daí a dificuldade dessa tarefa, na medida 
em que os objetos do campo exogâmico não the assegurarão o afeto incondicional oferecido, ainda que ilusoriamente, pelas figuras parentais.

Nesse sentido, os movimentos de ruptura e de experimentação fazem parte do processo da adolescência, e se dão por meio do ensaio frente a escolhas de soluções provisórias nas situações para as quais o jovem ainda não possui recursos internos para reconhecer como genuínas (Macedo, Fensterseifer, \& Werlang, 2004). A sustentação das figuras parentais através de mediações simbólicas, da atribuição de significados à palavra e às angústias adolescentes, torna-se essencial nesse processo. Percebe-se, assim, a relevância que adquirem as situações nas quais as falhas nessa função das figuras paternas podem ser vivenciadas como desamparo e desencadear maior fragilidade na organização psíquica, adquirindo um caráter traumático para o adolescente, conforme verbaliza a entrevistada:

Tu escutas e tu te preocupas, o que pode acontecer entre uma sessão e outra. Por quê? Porque esse sujeito não está só com a falta de recursos próprios da sua idade; ele está com falta de recursos na organização de si mesmo. (P10).

Os psicanalistas entrevistados observam, em suas práticas clínicas, o modo como as expectativas narcísicas dos pais também podem se instalar no campo da psicopatologia na medida em que impossibilitam ao adolescente constituir sua história como sujeito singular. Nessas situações, percebese a imposição no campo intersubjetivo de demandas parentais que invadem o espaço do adolescente. A violência implícita aí contida pode ser comparada com o que disse Hornstein (2008) a respeito da importância do ritmo entre a fusão e a separação do bebê com a mãe, no processo de narcisização da criança. Da qualidade desse encontro dependerá, segundo o autor, o significado atribuído ao outro, o qual poderá representar uma presença estruturante ou uma presença arrasadora.

Segundo os entrevistados, esses aspectos surgem de diferentes maneiras:

O que está caracterizando a nossa clínica da contemporaneidade? Esses adolescentes chegam atravessados pela expectativa narcisista dos pais. Só tem um lugar, o primeiro. (P10).

A turbulência que é normal na adolescência é muito mal tolerada pela família, pelo adolescente, porque tem o reforço muito importante do contemporâneo de uma proibição de sentir sentimento. (...) A questão da subjetividade está profundamente comprometida, porque seu destino está traçado desde que nasceu. Ele vai ser o representante do sobrenome tal, vai herdar a empresa tal, e ai dessa criança ou desse adolescente que nasceu com dom pra ser músico, por exemplo. O gatilho está numa impossibilidade do adolescente de conter a sua ansiedade própria do período e a família muito pouco continente. (P4).

Constata-se neste estudo que as configurações familiares contemporâneas no processo adolescente foram citadas muitas vezes pelos psicanalistas entrevistados. A educação dos filhos é considerada um desafio nos tempos atuais, contemplando aspectos que vão além dos conflitos de gerações comumente experimentados. Segundo Mayer (2001), impõe-se, na contemporaneidade, um mundo globalizado em um cenário de mudanças em intensa aceleração. Nessa perspectiva, discute-se o lugar da responsabilidade e dos limites na família. Parece haver um constante desprestígio da função paterna e a consequente dificuldade do exercício das funções de adulto de referência, constatandose que, de forma frequente, os pais se colocam em posição de equidade com os filhos. O relato dos entrevistados exemplifica a confusão dos papéis das figuras parentais, em um contexto denominado novas configurações 
familiares, identificado a partir da escuta analítica:

Uma coisa um pouco atrapalhada é a questão de limites em relação à família. A mãe, o pai muito atrapalhados no sentido de quem é o pai e quem é a mãe, quem manda em quem, pais saindo com os filhos e mães saindo com as filhas. (P5).

Todavia, percebe-se, no relato do entrevistado P9, que as novas configurações familiares podem ser também entendidas como benéficas para os adolescentes:

Acho um pouco preconceituoso partir de uma ideia de simplesmente que as relações instáveis, as novas buscas amorosas, o segundo, terceiro, quarto casamento, a presença de irmãos em configurações muito variadas, de idades muitas vezes divergentes, de que isso por si só implicasse numa patologização dos processos. (P9).

Constata-se que, independentemente da configuração familiar, o que prevalece como condição importante no processo de subjetivação adolescente é a observância da qualidade das relações estabelecidas assim como um exercício das funções parentais por meio do qual a condição de desamparo ou de excesso não se faça presente. Sobre esse aspecto, o participante destaca:

Pais mais voltados para si mesmos, mais ocupados com suas coisas, com suas questões e então, dão aquelas respostas: 'Chega a hora que tu quiseres' ou 'Quando terminar tu vem'. Isso dá uma desorganização e um desamparo nesse sujeito. Ele precisa que o outro diga: 'Tu vem à meia noite'. E ele vai dizer: 'Mas à meia noite recém está começando'. 'Pois é, mas eu vou te buscar à meia noite'. Isso não é da ordem da rigidez, é da ordem da organização. (P10).

Nessa perspectiva, trata-se de reconhecer a relevância e a necessidade de um espaço intersubjetivo no qual os papéis, necessariamente assimétricos, estejam bem definidos, e os limites possam ser exercidos no sentido de promover um processo de subjetivação adolescente no qual reconhecer a diferença se associe a fatores de cuidado e proteção. Concomitantemente às questões próprias das experiências do campo endogâmico e às novas possibilidades de configurações familiares, outro aspecto abordado pelos participantes é a temática dos limites, considerado fator ordenador e estruturante do aparelho psíquico. O conceito psicanalítico de castração, à luz de seu sentido organizador do psiquismo, procura dar conta da temática dos limites, da constatação e da aceitação da finitude e da incompletude humana, abrindo, assim, o registro da falta e, por conseguinte, dando condições para que surja um espaço para o desejo.

Por meio da possibilidade de desejar, Pinheiro considera que se pode abrir mão da condição ilusória de completude própria da infância. Para a autora,

sair da ilusão da suficiência é entrar no mundo da parcialidade, é ter que conviver, daí para frente, com a dimensão solitária da vida, com o não partilhável das relações de objeto que algumas vezes possibilitam encontros e, outras, desencontros (2001, p.74)

Enfatiza-se que aceitar a castração seria, também, uma das tarefas psíquicas próprias da adolescência. A partir dessa aceitação, dá-se o ingresso do sujeito no mundo adulto, no qual o aspecto solitário da vida não alude mais, necessariamente, a uma situação a ser evitada, mas, ao contrário, passa a ser por meio dela que o sujeito poderá se abrir aos diversos investimentos do campo exogâmico. Ocorre que, na atualidade, segundo Rocha e Garcia (2008), a adolescência ocupa na sociedade um lugar de ideal cultural. No processo de reorganização narcísica, o desafio reside em manter papéis que, em um contexto idealizado, impedem que se cumpra a castração, na medida em que esses adultos acenam aos adolescentes com uma promessa 
de prazer sem limites. Afirmam os autores que "ao esperarmos que a adolescência, como ideal cultural, cumpra a promessa de burlar a castração, colocamos para o adolescente um impasse a mais nesse momento crucial do processo de subjetivação" (Rocha \& Garcia, 2008, p. 630). Também há essa constatação no depoimento do entrevistado:

Há simplesmente uma necessidade de cumprir um ritual imposto por uma cultura. É muito perverso, pois a adolescência já é um período de transição, daquilo que você não é para aquilo que pode advir. É um período muito delicado, no qual seus potenciais estão despontando, precisam ter espaço para aparecer a fim de compor a sua singularidade humana. (P2).

Influências no processo de construção da identidade do adolescente advindas do contexto social, quando remetem a demandas intensas que impossibilitam um trabalho de metabolização ou de atribuição de significado, extrapolam a possibilidade de contribuir para um processo saudável de subjetivação, e constituem experiências de excesso. Lerner (2007) afirma que essas interferências têm relação com o conceito de trauma, na medida em que impedem que o indivíduo seja, que consiga conquistar o eu sou. Pode-se afirmar que essa dinâmica ocorre devido à existência de um cenário instável e falho no suporte parental, no qual as exigências sociais podem vir a incrementar dificuldades típicas da adolescência, repercutindo como excesso aquilo que o psiquismo não possui recursos para processar. Hornstein (2008) afirma que, quando há exposição a quantidades não processáveis de trauma, os efeitos são destrutivos, salvo quando, por meio de elaborações (individuais e coletivas), tais quantidades possam ser simbolizadas. Assim, Lerner (2007) destaca que o adolescente precisa ter um solo firme durante o seu processo de desenvolvimento para experimentar e construir seus projetos.
No processo de expansão de seus horizontes endogâmicos, um dos cenários primeiros de experimentação do adolescente é a escola. Sabe-se que aquilo que foi experienciado no cenário familiar com matizes de ausência ou de excesso se reproduzirá nas relações escolares. Trata-se dos efeitos do vivido no processo de transição daquilo que é da ordem do espaço endogâmico para o campo exogâmico. Segundo Zimerman (2003), a escola constitui um espaço no qual a existência de problemas é inevitável, o que, por si só, não se tornaria algo preocupante. O autor considera que "problema, mesmo, consiste na inexistência da criação de apropriados espaços na escola, onde as distintas problemáticas possam ser ventiladas e debatidas" (p.17).

A escola serve de ponte para ajudar os pais a verem a necessidade. E por outubro, novembro, começa a ter muita procura, porque tem o risco da reprovação. Isso chama os pais para a escola, o medo da reprovação. E eles começam a escutar que não é isso, que atrás da reprovação tem outras coisas. A escola detecta e, em minha opinião, tem detectado muito bem. (P1).

A escola oferece ao jovem um mundo de investimentos psíquicos que o confrontam com outras exigências e, por ser um espaço ampliado, que extrapola os limites da esfera do núcleo familiar, há mais olhares e, em consequência, maior probabilidade de que sejam detectadas e percebidas dificuldades tanto intrapsíquicas como intersubjetivas. O desafio dos profissionais educadores é saber lidar com o que irá emergir e preocupar-se com a estrutura relativa à transmissão do conhecimento. Não seria possível à escola manter-se excluída das problemáticas típicas dessa idade. O que se reafirma é a relevância de que nela não se ausente a capacidade de atenção àquilo que se mascara nos ditos comportamentos desafiadores, transgressivos, delinqüentes (Zimmermann, 2007), ou seja, é relevante que a escola não perca de vista sua influência no processo de ressignificação 
da identidade adolescente. Cabe, porém, à escola demarcar diferenças entre sua função formativa e a apropriação do exercício de funções parentais. Como descrito nas verbalizações a seguir, percebe-se que a escola tem se consolidado como importante espaço denuncia-dor:

Muitas vezes, os familiares são conduzidos à busca de terapia por uma demanda da escola, de um cursinho pré-vestibular. É ainda outra instituição externa à família que detecta alguma coisa no comportamento do adolescente e pede uma avaliação psicológica. Muitas vezes, a demanda está relacionada a uma produção cognitiva, uma produção escolar, uma baixa produção, ou uma dificuldade de relacionamento. (P2).

As experiências de amparo e desamparo frente ao processo da adolescência têm, nas relações familiares e na escola, os campos primordiais de experiência intersubjetiva. $\mathrm{O}$ espaço exogâmico carrega em si exigências para o enfrentamento de diferentes demandas frente às quais o adolescente precisa lançar mão de recursos psíquicos. No campo dessa temática, estrutura-se a segunda categoria final: necessidade de recursos psíquicos: exigências para o enfrentamento do processo de ressignificação de si mesmo.

Sabe-se que o impacto gerado pela transição da infância para a adolescência e suas decorrentes demandas emocionais e físicas podem constituir naturalmente uma fonte de angústia; é necessário considerar, porém, que a adolescência, como um processo típico e não necessariamente patológico, abarca situações de crise e de enfrentamento e conflitos típicos dessa fase da vida. Ainda que permeado por movimentos de dúvidas e dificuldades, o sofrimento adolescente não implica, necessariamente, a instauração de um padecimento psíquico. Essa faixa etária pode, portanto, ser definida como um período crucial de reorganização identificatória, uma vez que novos significados desencadeiam movimentos em sua trama que determinam mudanças na subjetividade (Palazzini, 2007). Essas mudanças têm repercussões nos investimentos do adolescente. O grupo de amigos, por exemplo, torna-se uma grande fonte de identificação, por meio do qual "as atividades cotidianas compartilhadas podem revelar uma tentativa conjunta de elaborar impasses relativos ao laço social contemporâneo" (Cairoli \& Gauer, 2009, p. 210). Os ideais políticos e sociais, historicamente uma das forças motrizes do mundo adolescente, são cada vez mais confrontados com realidades nas quais o egoísmo e a falta de solidariedade imperam (Lerner, 2007). Tais questões demonstram uma realidade política e social oposta, podendo adquirir efeitos traumáticos quando se pensa pela via do desamparo a que é exposto o adolescente.

A queixa que vem dos adolescentes gira muito em torno das questões afetivas e dos relacionamentos, das iniciações sexuais. É uma questão que me chama a atenção nos últimos cinco anos pelo menos, esse enfoque nas pessoas jovens, adolescentes que chegam angustiados com essas primeiras experiências. (P6).

Sabe-se que a sexualidade não tem início na adolescência, mas é nesse período que o desenvolvimento psicossexual inaugura um novo tempo, no qual o autoerotismo infantil evolui gradualmente para a etapa da genitalidade, culminando com o desejo sexual a partir do encontro com o outro que visa a atender novas vicissitudes pulsionais. Constata-se que, na contemporaneidade, ao mesmo tempo em que há ainda resquícios do ideal amoroso romântico, surgem novos tipos de relacionamento. O ficar, por exemplo, da mesma forma que se institui como nova forma de sociabilidade, provoca rupturas entre o ideal e a realidade, podendo reforçar determinado modo de lidar com os sentimentos, caracterizado pela busca de prazer imediato e pela falta de compromisso com o outro (Chaves, 2001). 
Nessa perspectiva, o entrevistado P7 ressalta:

O adolescente, frente à dificuldade com sua iniciação sexual, acaba encontrando essa oferta da cultura para fazer a sua iniciação como algo banal; o significado dessa situação é destruído e apresentado como uma variante natural da sexualidade. (P7).

Demandas advindas do contexto contemporâneo referentes ao uso que a sociedade faz de um poder que se presentifica por meio das altas exigências associadas às possibilidades de reconhecimento social e cultural têm sido motivo de constante reflexão na clínica. Conforme destacaram os entrevistados, a cultura, como excesso, pode incrementar, ou mesmo desencadear o padecimento psíquico adolescente:

Tudo está na ordem do excesso. É o excesso da internet, é o excesso dos jogos. Tudo num modelo da sexualidade, da masturbação. A excitação, o prazer, o gozo, estão no jogo, está na internet. Está falhando o prazer de encontrar com o outro. (P10).

Muitas vezes esse contexto contemporâneo abafa a construção da subjetividade. É a negação de qualquer sofrimento psíquico. No contemporâneo, sofrer de algum tipo de depressão, de ansiedade, é proibido. (P4).

A cultura e a forma de organização da sociedade contemporânea têm sido bastante discutidas à luz de seus benefícios e prejuízos. Silva (2007) considera que a sociedade a que Debord (1997) se referiu como uma sociedade do espetáculo, marcada pela contemplação do outro idealizado e a consequente delegação daquilo que se julgava inatingível, não existe mais. Segundo o autor, estamos em tempos de hiperespetáculo, experimentando "uma contemplação de si mesmo em um outro, em princípio, plenamente alcançável" (p.31). Para Silva, trata-se de uma cultura do imediatismo ao alcance de todos, na qual se tem, na imagem, seu principal produto. Assim o hiperespetáculo "não é um conjunto de imagens, mas uma imagem única, sob a aparência de diversidade, que não permite reflexão" (Silva, 2007, p.33). Esse aspecto se faz presente nas colocações dos entrevistados:

Tudo do nosso contexto sociocultural que propõe uma alienação da subjetividade em favor de um modelo único é produtor do sofrimento psíquico. (P2).

Parece que tudo vai ser resolvido na superfície, e não por uma medida de profundidade, mudanças na aparência, a ilusão de que há soluções rápidas e imediatas para tudo. Esse conjunto de fatores da nossa cultura empobrece significativamente a capacidade simbólica. (P7) .

Nesse contexto, o adolescente, além de características inerentes ao sofrimento típico dessa etapa, tem vivenciado experiências que nem sempre contribuem positivamente para seu processo de subjetivação. Retomando a questão da economia dos recursos psíquicos e do padecimento adolescente, Lerner (2007) propõe uma reflexão sobre o que diferencia um adolescente que naufraga de outro que segue navegando; cabe, portanto, um questionamento a respeito de aspectos que contribuem para que um aparente sofrimento típico do processo adolescente se desvele como patologia. Segundo o autor, a história da construção subjetiva do adolescente que avança sem maiores dificuldades nesse processo permite constatar o acesso a recursos de plasticidade do eu, fazendo com que ele possa recorrer a diferentes modalidades de navegação para atravessar tormentas sem naufragar. Não se trata de desconsiderar, portanto, a existência de conflitos na adolescência, mas sim, de constatar que, diante da fragilidade de recursos psíquicos, pode o adolescente submergir em padecimentos, tais como a depressão e as patologias do ato.

Trata-se de destacar o valor de inserção em um contexto que lhe oferece novas 
possibilidades identificatórias, constata-se, porém, da mesma forma, que, diante das ofertas da sociedade contemporânea, pode surgir um hiato entre o que o sujeito é e o que ele deseja ser. Fortes (2008) assinala o quanto não se pode desconsiderar o vazio subjetivo que se presentifica na atualidade como um efeito do excesso, ou seja, das modalidades ofertadas pela sociedade contemporânea. Esses efeitos danosos na produção de subjetividade denunciam o alto custo de uma existência regida pela performance. Na fala dos participantes, encontram-se evidências do contraste entre a vida agitada dos adolescentes, a ausência de limites no domínio das tecnologias e a escassa capacidade de investimento e de conhecimento sobre si mesmo:

É mais uma coisa de pessoas meio desinteressadas pela vida. Apáticas, inteligentes, com capacidades, às vezes até com bom rendimento escolar, mas um escasso investimento na vida. Retraídos, mais isolados. Uma vida social relativamente pobre. (P9).

O que mais tenho visto é uma apatia na adolescência. Pais que chegam dizendo que falta ânimo e falta vida. São adolescentes que chegam e não sabem bem porque estão chegando, não sabem bem o que querem. Ele nem sabe dizer qual é o problema. E aí, tu tens que fazer um trabalho, um trabalho prévio. Como se tu tivesse que criar bases de uma estrutura psíquica, para depois, um dia, esse adolescente vir a saber o que incomoda. (P1).

Ao abordar a temática da apatia, considerando-a como uma manifestação frequente da adolescência contemporânea, Aryan (2006) demarca que o adolescente não tem demonstrado desconforto quando não é confrontado, tampouco se responsabiliza quando não é convocado. Parece, assim, não ter ideias além daquilo que percebe como imprescindível, o que denuncia sua passividade. Frente ao empobrecimento do si mesmo e à escassez de recursos para dar conta daquilo que requer seu envolvimento afetivo, fazem-se presentes o desânimo e a constatação do desamparo frente à intensidade do que experimenta.

\begin{abstract}
Que esse sujeito possa estar desorganizado, que possa estar atrapalhado, que não saiba onde vai pôr as pernas, a sexualidade, os braços, não teria importância, se ele encontrasse no outro, no semelhante, um vetor de apaziguamento para isso, mas um apaziguamento que não seja traumático, ou seja, que não é: 'Isso que está se passando contigo se passa com todo mundo', Não, isso é enlouquecedor. Que pudesse encontrar num semelhante alguma coisa que dê conta da singularidade dele. (P10).
\end{abstract}

Desde o nascimento, o bebê, vulnerável e dependente, necessita do outro para se desenvolver. O sujeito, portanto, constituise na relação com o outro. Assim, na adolescência, as questões da alteridade se enlaçam com tais problemáticas, e são claramente observadas a partir da experiência dos psicanalistas participantes deste estudo. $\mathrm{O}$ papel do outro na saúde psíquica é, portanto, crucial ao longo do desenvolvimento e do processo de subjetivação. Nessa perspectiva, a entrevistada P10 complementa:

O déficit de atenção é a atenção afetiva; esse sujeito não consegue prestar atenção, esse adolescente de hoje não consegue reconhecer o lugar que o outro ocupa. Ele não sabe qual é o lugar dele. Então ele não reconhece ninguém, ele acha que pode fazer tudo. (P10).

A necessidade de o adolescente construir sua subjetividade por meio de um espaço mediado por um outro estável no qual ele possa acreditar é destacada por Aryan ao afirmar que "poder acreditar é uma consideração imprescindível para conceber metas alcançáveis, encontrar objetos sexuais exogâmicos válidos e efetuar as sublimações necessárias" (2006, p. 231). A subjetividade do adolescente estará, inegavelmente, marcada pelo efeito do vivido em etapas anteriores de sua vida. 
Outro aspecto da contemporaneidade que se faz presente, ao abordar a temática da adolescência, diz respeito aos recursos virtuais cada vez mais presentes e imprescindíveis na vida cotidiana. A virtualidade torna-se, cada vez de modo mais imperativo, outro campo exogâmico para o processo de construção da subjetividade. São irrestritas as possibilidades oferecidas pela rede mundial de computadores, dos sites de relacionamentos aos programas de mensagens instantâneas, todos maciçamente utilizados pela sociedade, mas, em especial, pelos adolescentes. Como não poderia deixar de ser, essa é, também, uma temática na clínica com adolescentes.

Isso criou uma transformação tanto em nível de comunicação, porque quinze anos atrás, vinte anos atrás, se ouvia muito os pais dizerem 'fulano não desgruda do telefone'. Isso não existe mais, ninguém mais está grudado no telefone; estão grudados na rede, estão grudados no MSN, estão grudados no youtube, no Orkut. (P9).

O adolescente vive em um tempo onde não há espera, tudo é imediato. Hoje em dia, a gente vê um adolescente aborrecido porque depois de ele ter dado um comando, famoso 'duplo click' no mouse, ele tem que esperar alguns segundos para que alguma coisa carregue, para que a pessoa, do outro lado do MSN, responda. (P2).

Ele tem seu grupo de iguais, conversam, mas ele está com uma retração da libido, está voltado para as relações pela internet. (...) Esses vínculos acabam ficando empobrecidos, porque são virtuais. $\mathrm{Na}$ hora do encontro, realmente, as coisas ficam difíceis. (P1).

A internet se apresenta como um cenário contemporâneo no qual as dúvidas, as inquietações, os conflitos, as incertezas sobre a sexualidade marcarão presença sob diversas formas. Assim, no espaço virtual, o sujeito pode rapidamente criar vínculos e romper barreiras em relação a distâncias físicas, mas também pode promover massificação, vínculos superficiais, submissão a um modelo que impede a privacidade e a genuína intimidade com o outro. Na complexidade dos tempos atuais, cabe refletir sobre os efeitos decorrentes dos avanços possibilitados pelos recursos virtuais e sobre a máxima de prazer imediato na adolescência.

A temática da sexualidade não poderia ficar à mercê dessas mudanças; assim, adentrar o campo da sexualidade segue despertando importantes questões na adolescência. O tema da homossexualidade, bem como o da bissexualidade na adolescência, se faz presente nesse cenário devido a seus enlaces com a cultura do imediato. Esse prazer imediato oferecido pela cultura e pela mídia denota um prazer adicto, que não passa pela mediação do outro, produzindo apenas uma descarga instantânea (Maia, 2004). Os entrevistados evidenciam esse aspecto:

A internet também tem tido o papel de fomentar e incrementar as fantasias sexuais, e isso deixa eles mais angustiados e ansiosos, sem saber o que fazer com o que eles veem e conversam através da internet. (P6).

Em casos possivelmente de uma escolha homossexual, algumas coisas vêm pelo adolescente, com uma demanda desviada, mascarada como 'tem dificuldade para se relacionar'. E à medida que as entrevistas de avaliação vão prosseguindo, aparece essa questão, a dificuldade para se relacionar com o sexo oposto e o desejo de se relacionar mais intensamente com as pessoas do mesmo sexo. (P2).

Em outros momentos culturais, esses conflitos sexuais teriam outro tipo de solução. Eles não passariam com tanta facilidade para a ação, não teria essa passagem ao ato com tanta facilidade como uma oferta excessiva de uma sexualidade ou pervertida ou distorcida, oferecida como um produto de consumo acessivel. (P7).

Nesse sentido, a atividade sexual, quando carrega em si a marca de intensa angústia que não pôde ser metabolizada, pode ser pensada à luz de outras manifestações que envolvem o 
corpo, também nomeadas como passagem ao ato (Savietto \& Cardoso, 2006; Coutinho, 2006). Na rapidez do mundo virtual, passa a imperar o autocentramento e a busca de atender todas as demandas a fim de evitar registros de falta ou incompletude. Tais manifestações vêm sendo observadas com reqüência na clínica, e, segundo Savietto e Cardoso, isso se dá como uma resposta à angústia, por não se suportar o desprazer e pela impossibilidade de recusa ao adiamento do prazer imediato.

Lá pelas tantas, quando começa a aparecer a questão da angústia, começa a aparecer também o uso da maconha, da bebida ou de outras coisas como um fator que ajuda às vezes a chegar nas meninas, a se desinibir ou a lidar com aquela frustração. (P6).

O tipo de recurso escolhido pelo adolescente para suprimir a sua dor ou para atingir a satisfação dependerá "do contexto, do momento e daquilo que, na experiência individual, tenha mostrado maior eficácia" (Mayer, 2001, p.84). Mayer sublinha que, diante da falta de ideais e da intolerância à frustração, as vidas desses adolescentes estão "impregnadas de um sentimento de tédio e de uma vivência de futilidade que virão a reclamar um choque de adrenalina que Ihes dê sentido. Não importa muito se esse choque é conseguido roubando, matando ou matando-se com substâncias psicoativas" (p. 98).

Muitas vezes o uso de drogas é a única saída de busca de subjetividade. Claro que cada caso é um caso, pode funcionar como um antidepressivo ou como uma fuga, mas alguma vez me parece que a gente tem que pensar também no sintoma como uma busca de subjetividade. (P4).

Muitas vezes, o que observamos é que realmente o álcool e a droga estão funcionando como antidepressivos para vazios ou melancolias muito precoces que, obviamente, não conseguem suprir, e vão cada vez mais adoecendo esse adolescente.

(P8).

Fica evidente, também, a partir das verbalizações dos psicanalistas entrevistados, que o uso do recurso da descarga no corpo aparece como uma alternativa do adolescente frente às experiências do processo de subjetivação. Outro aspecto próprio do contexto contemporâneo que pode favorecer ou desencadear padecimentos psíquicos, exigindo maior capacidade de recursos dos adolescentes no seu processo, diz respeito aos efeitos da violência.

Tem uma coisa da nossa cultura que produz um efeito, também muito forte, que é a insegurança. Essa questão da violência. (...) Isso tem um efeito de produzir pessoas mais assustadas, mais medrosas ou, dependendo da constituição da pessoa, mais arrogantes, onipotentes. (P3).

Esse sujeito chega na adolescência com repetições de desamparo a si próprio. A situação violenta da realidade potencializou, quase como a teoria do apoio que Freud diz lá do início, deu apoio, deu carona para que isso aparecesse. Então, se descortina o que está por trás. (P10).

A partir das exigências oriundas do cenário contemporâneo, é possível pensar na sobreposição de demandas às quais está submetido o adolescente. Ainda que os motivos de busca de um tratamento possam variar, sabe-se que, normalmente, o que impulsiona a busca por ajuda refere-se a um sofrimento que o sujeito experiencia como se não conseguisse vivenciá-lo sozinho. Trata-se de reconhecer um limite frente aos recursos de enfrentamento com uma situação conflitiva e produtora de dor psíquica, abrindo espaço para que outro possa auxiliálo. É imprescindível, portanto, refletir sobre os efeitos que terá essa sobreposição na escuta clínica. O cenário da clínica psicanalítica é habitado por padecimentos complexos e singulares, que desafiam constantemente o 
analista no exercício de sua escuta. Nesse sentido, é fundamental propor a terceira categoria final, que recebeu o nome de desafios e inquietações no campo analítico: especificidades teóricas e técnicas a partir da escuta de adolescentes.

Na proposição de pensar o que leva um sujeito ao espaço clínico, destaca-se o papel da dor psíquica como propulsora do encontro com o outro, desconhecido, mas a quem se atribui uma capacidade de ajuda. $\mathrm{O}$ campo analítico é, por excelência, o campo do encontro entre alguém que demanda ajuda e outro que se propõe a escutá-lo.

Coloquei o acento no aspecto social, familiar, contemporâneo, mas me parece que continua muito válida aquela máxima de que tem que escutar cada adolescente que vem, e de onde vem, o seu sofrimento. (P4).

Cada um se manifesta de um jeito, negando o sofrimento, desmentindo, se atrapalhando ou se confundindo, seja o que for. Com isso se amplia o alcance da análise, se amplia o alcance do método psicanalítico. (P10).

A vivência de ser escutado como sujeito na singularidade de seu padecimento possibilita uma atribuição única de sentido às suas dores. Segundo Macedo e Falcão, o processo analítico "deve possibilitar a descoberta, por parte do paciente, de que ele é quem sabe de si: um saber que é patrimônio de um território desconhecido de si mesmo. Para alcançá-lo, além de ser escutado, o paciente deverá escutar-se (2005, p.69)". As autoras reforçam a ideia de que o analista exercita, de fato, a escuta analítica quando se coloca no lugar de alguém que não sabe a respeito daquele que chega com um sofrimento.

No desafio de compreender as demandas da clínica do adolescente, os participantes deste estudo destacaram, a partir de suas interrogações acerca do sintoma, a complexidade que se faz presente nas configurações de sofrimento na contemporaneidade. Fiel aos ensinamentos da psicanálise, tal constatação segue inviabilizando uma leitura linear do padecimento psíquico, bem como aponta a constante necessidade de interrogações e a ampliação dos recursos que habitam o setting analítico.

É impossível trabalhar com o adolescente dentro de um standard, de uma postura que tu tens com o adulto. Daqui a pouco ele está mexendo no computador, eu estou em pé, eu circulo... Essa plasticidade é inerente ao trabalho com adolescente. (P9).

Trabalhar com essa faixa etária é um desafio muito grande. Acho que é a faixa etária mais estimulante e viva dentro do consultório. É onde mais acontecem coisas, onde mais aparece o inesperado. (P1).

Para Kupermann (2007), o estabelecimento do vínculo no atendimento do adolescente é uma condição fundamental. Por outro lado, é necessário refletir sobre os efeitos do contexto contemporâneo em um setting que já carrega em si particularidades:

Como vamos encarar, por exemplo, uma frustração de uma demanda num setting analítico? Uma não gratificação? Isso acredito ser uma característica da nossa contemporaneidade e do tempo presente, que advém da evolução dos meios de comunicação e, sobretudo, da comunicação em rede e virtual, em tempo real. Esse é um desafio grande, que nós temos. (P2).

O principal requisito técnico para trabalhar com adolescente é ter presente a própria adolescência. Isso é fundamental, porque senão o teu olhar acaba sendo um olhar muito atravessado só por uma outra coisa que evidentemente é ser um adulto. Tenho noção das diferenças deles comigo, e que a minha fala, que o meu discurso vai chegar neles como a fala de um adulto. Eu não falo com eles da maneira como um amigo fala, como um colega fala. Eles têm uma forma própria de se expressar que não é a minha, mas, ao mesmo tempo, tenho que ter sempre presentes questões da minha própria adolescência. (P9). 
Para Levisky (1995), da mesma forma que foram criadas técnicas para a análise de crianças, adaptações oriundas de elementos do tratamento infantil e adulto foram sendo desenvolvidas para atender o adolescente. Em consonância com a fala do entrevistado P9, o autor assevera ser esperado do analista de adolescentes que ele, além de gostar e de ter interesse pelas questões relativas a essa fase do ciclo vital, seja capaz de estabelecer, em sua personalidade, condições de flexibilidade e adaptação para fazer frente às condições psíquicas da adolescência. No mesmo sentido, e ainda destacando a importância do lugar ocupado pelo analista nesse singular espaço de escuta, os entrevistados relatam:

Acreditar que tu não vais ocupar o lugar de educador ou de pai ou de superego e também não vais ficar na farra de um grupo de iguais e também não vai tratar como criança. É um lugar muito delicado, esse. Tecnicamente, eu aprendi com eles, talvez mais do que nos livros, por experiência, que estabelecer uma relação de confiança é a minha meta no início. (P1).

É um tratamento às vezes um pouco mais curto, mais dinâmico. Com certeza eles se beneficiam bastante, e redimensiona a vida deles num espaço de tempo às vezes até mais curto do que de um adulto. É um momento importante da vida para poder se pensar, e evitar até muito sofrimento futuro. (P6).

O objetivo da análise com adolescentes consiste na possibilidade de autorizá-los, nos seus atos e até mesmo nos seus sintomas. Em resposta a um agir sintomático, é fundamental que o analista possa intervir também pela via da atitude continente, em uma dimensão ética a qual, além da clássica interpretação e de intervenções discursivas, envolve um trabalho com os elementos do setting relacionados especialmente às combinações do contrato (Coutinho, 2006). Assim, há que se considerar que, na adolescência, período no qual os modelos identificatórios são especialmente importantes, o papel do analista adquire relevância durante todo o processo:
Esse é um ponto delicado, pois o adolescente está muito dentro de uma cultura do imediatismo, de tudo conseguir rápido. Então, entrar numa combinação de frequência, que tende a ser um processo diferente do que ele está acostumado, não é muito fácil; dá trabalho. (P3).

Quando comecei a receber adolescentes ou pessoas mais jovens, a outra questão que ficava para mim era: divã ou não divã? Qual a frequência? E por uma resistência, uma dificuldade minha de pensar um adolescente num divã. Foram experiências até agora muito boas, de pacientes jovens, adolescentes, com divã e com resultados muito produtivos. Claro que nem todos que vieram ficaram, mas os que vieram e ficaram se beneficiaram bastante da análise. É bem pertinente poder questionar a análise com adolescentes. (P6).

Percebe-se que, ao levar em conta as características da adolescência, o uso do divã pode ocorrer ou não no tratamento de adolescentes. Tal temática desperta importantes questionamentos e reflexões quanto à técnica psicanalítica. Os impasses sobre o uso ou não do divã fazem com que, da perspectiva do analista, seja necessário identificar o momento e a viabilidade do uso desse recurso, observando sempre a singularidade do paciente adolescente. Considerando-se as questões da contemporaneidade abordadas no que diz respeito à adolescência, chega-se às transformações nos recursos técnicos, as quais, segundo os psicanalistas entrevistados, contribuem para as transformações no espaço clínico.

O computador é hoje em dia quase um instrumento indispensável no meu consultório em função dos adolescentes. Porque é muito comum que eles me tragam fitas, cds ou que queiram me mostrar alguma coisa na rede. Isso se torna uma coisa fantástica para ele como era no passado um material gráfico para fazer um desenho, para pintar alguma coisa. (P9).

$A$ atendi um adolescente que veio com violão, porque canta. Na música, ele consegue escrever o que pensa. Temos que ter essa abertura, pensar que a análise não 
é uma coisa 'trancadinha' para adolescente, ter uma capacidade de tolerar que tu não sabes o que vai acontecer na outra sessão. Isso, desse inesperado, é uma coisa bem boa, mas tu tens que estar preparado para um inesperado às vezes mais barulhento. (P5).

De outra perspectiva, a entrevistada P2 cita mais um desafio ante as demandas da clínica:

O que nós encontramos muitas vezes são adolescentes que trazem, por exemplo, letras de música ou artigos de jornal, mas é um discurso de um outro, pela perspectiva de um outro. Na minha experiência, algo que me inquieta, e acredito que seja um dos maiores desafios que nós temos, é o resgate do lugar da palavra. (...) O risco que nós, analistas, corremos, no meu ponto de vista, é perdermos a questão central da palavra, deixarmos de lado e começarmos a importar outro tipo de recurso, exatamente porque a palavra está esvaziada. E há uma tentação muito grande de que isso seja feito, sobretudo na clínica com adolescentes. Se o adolescente fala pouco, não faz mal, então vamos fazer um jogo de computador. Não, se o adolescente fala pouco, vamos confrontá-lo com a sua pouca fala. (P2)

Segundo Aryan, o analista deve mudar sem perder aquilo que ele denomina linguagem fundamental psicanalítica. O autor enfatiza que o analista deve gerar transformações sem perder de vista as questões éticas e a regra básica de abstinência da sua parte. Para o autor, no entanto, essa regra não se refere a uma inação (não ação), mas à capacidade de preservar o analista dos desejos que obstaculizem "o contato do paciente com seu mundo interno e o desejo de se responsabilizar por si próprio. Por isso penso que o psicanalista deve ser um agente ativo nessa função" (2006, p.238). É fundamental destacar, em relação às falas dos entrevistados, que, independentemente do recurso técnico escolhido pelo analista para escutar a singularidade da dor do adolescente, há uma dimensão ética para além dos aspectos deontológicos da profissão, implícita nas reflexões propostas. Pensar sobre o seu fazer denota uma condição essencial para o exercício de uma prática efetiva bem como para a evolução da técnica. Nesse sentido, entende-se que ética e técnica são ações mutuamente implicadas.

Diante do exposto, acredita-se que será no espaço de escuta analítica que a demanda adolescente poderá ser desdobrada em seus significados singulares. Constata-se, nos dizeres dos entrevistados, essa preocupação de refletir sobre recursos teóricos e técnicos que sigam abarcando as transformações presentes nas formas de expressão do padecimento adolescente contemporâneo. Na medida em que a adolescência é compreendida como um momento fundamental de ressignificação da identidade, é inegável ser por meio das configurações de seus padecimentos psíquicos que se dá a possibilidade de acessar e de compreender os efeitos do contexto sociocultural no processo de subjetivação, bem como se impõe a reflexão a respeito de seus possíveis desdobramentos na clínica psicanalítica atual.

\section{Considerações finais}

O estudo realizado buscou explorar e compreender as demandas e as configurações de padecimentos psíquicos da clínica da adolescência no contexto contemporâneo. Entende-se, dessa forma, ser necessária e pertinente uma reflexão sobre os efeitos das complexas demandas atuais dessa faixa etária. É importante considerar que, ainda que o processo da adolescência tenha, em alguma medida, um caráter universal, acredita-se que o modelo psicanalítico de escuta da singularidade humana possa abarcar aspectos únicos que se fazem presentes nos matizes de padecimento do adolescente. Reconhece-se, dessa forma, a sua inserção em um contexto social e cultural, mas reafirma-se a singularidade dos fatores envolvidos no seu processo de subjetivação. 
Na medida em que o encontro analítico visa a atribuir sentido à dor adolescente e a viabilizar desdobramentos saudáveis nas mais diversas esferas de sua vida, a clínica é um campo privilegiado de qualificação do processo de genuíno autoconhecimento. Por outro lado, a maioria dos entrevistados chamou a atenção, durante as entrevistas, para o fato de haver poucos estudos empíricos que abordem a temática da escuta analítica de adolescentes, fato que vem se modificando na medida em que pesquisas em psicanálise vêm se consolidando cada vez mais nos espaços acadêmicos. Assim, este estudo abordou a escuta de analistas considerando uma clínica com suas especificidades. Trata-se, portanto, de seguir investigando a relação que se estabelece em outras condições sociais e culturais quando se torna necessário refletir a respeito das demandas que levam um adolescente a buscar ajuda na ocorrência de dor psíquica. Reafirma-se, com este estudo, a necessidade de o exercício da clínica psicanalítica continuar sendo a fonte instigadora de contribuições teóricas e de consistentes transformações na técnica psicanalítica. 
Renata Cardoso Plácido Ayub

Mestre em Psicologia, Pontifícia Universidade Católica do Rio Grande do Sul, Rio Grande do Sul - RS - Brasil. E-mail: renata.ayub@gmail.com

Mônica Medeiros Kother Macedo

Doutora em Psicologia, Pontifícia Universidade Católica do Rio Grande do Sul, Rio Grande do Sul - RS - Brasil.

E-mail: monicakm@pucrs.br

Endereço para envio de correspondência:

Rua Dr. Florência Ygartua, 69 conj. 307 Porto Alegre, Rio Grande do Sul - RS - Brasil. CEP 90430-010.

Recebido 28/5/2010, Aprovado 16/5/2011. 


\section{Referências}

Aryan, A. (2006). Novos objetivos na psicanálise de adolescentes? Psicanálise, 8(1), 229-242.

Bardin, L. (1988). Análise de conteúdo. Lisboa: Edições 70.

Birman, J. (2006). Tatuando o desamparo. In M. R. Cardoso (Org.), Adolescentes (pp. 25-43). São Paulo: Escuta.

Blos, P. (1998). Adolescência: uma interpretação psicanalítica (2a. ed). São Paulo: Martins Fontes.

Cairoli, P., \& Gauer, G. C. (2009). A adolescência escrita em blogs. Estudos de Psicologia, 26(2), 205-213.

Chaves, J. C. (2001). Amor e ódio nos relacionamentos afetivos da contemporaneidade. In M. R. Cardoso (Org.), Adolescência: reflexões psicanalíticas. Rio de Janeiro: Editora Nau.

Coutinho, L. G. (2006). Pensando sobre as especificidades da clínica psicanalítica com adolescentes. Latin-american Journal of Fundamental Psychopathology on-line. Recuperado em 20 maio 2009, de http://www.fundamentalpsychopathology.org/ journal/nov6/5.pdf

Debord, G. (1997). A sociedade do espetáculo. Rio de Janeiro: Contraponto.

Dockhorn, C., \& Macedo, M. (2008). A complexidade dos tempos atuais: reflexões psicanalíticas. Revista Argumento e Psicologia, 26, 217-224.

Fortes, I. (2008). A dimensão do excesso no sofrimento contemporâneo. Pulsional Revista de Psicanálise, 21(3), 63-74.

Hornstein, L. (1989). Introdução à psicanálise. São Paulo: Escuta.

Hornstein, L. (2008). As depressões. São Paulo: Via Lattera.

Kupermann, D. (2007). Sobre o final da análise com crianças e adolescentes. Estilos da Clínica, 12(23), 182-197.

Lerner, H. (2007). Adolescencia, trauma, identidad. In M. C. R. Hornstein (Org.), Adolescencias: trayectorias turbulentas. Buenos Aires: Paidós.
Levisky, D. (1995). Adolescência: reflexões psicanalíticas. Rio de Janeiro: Editora Nau.

Macedo, M. M. K, Fensterseifer, L., \& Werlang, B. S. G. (2004). Adolescência: um tempo de ressignificações. In M. M. K. Macedo (Org.), Adolescência e psicanálise: intersecções possíveis (pp.65-83). Porto Alegre: Edipucrs.

Macedo, M. M. K., \& Falcão, C. N. B. (2005). A escuta na psicanálise a psicanálise da escuta. Revista Psyché, 9(15), 65-76.

Maia, M. S. (2003). Extremos da alma: dor e trauma na atualidade e clínica psicanalítica. Rio de Janeiro: Imago.

Mayer, H. (2001). Passagem ao ato, clínica psicanalítica e contemporaneidade. In M. R. Cardoso (Org.), Adolescência: reflexões psicanalíticas. Rio de Janeiro: Editora Nau.

Palazzini, L. (2007). Movilidad, encierros, errancias: Avatares del devenir adolescente. In M. C. R. Hornstein (Org.), Adolescencias: trayectorias turbulentas. Buenos Aires: Paidós.

Pinheiro, T. (2001). Narcisismo, sexualidade e morte. In M. R. Cardoso (Org.), Adolescência: reflexões psicanalíticas. Rio de Janeiro: Nau.

Rocha, A. P. R., \& Garcia, C. A. (2008). A adolescência como ideal cultural contemporâneo. Psicologia: Ciência e Profissão, 28(3), 622-631.

Savietto, B. B., \& Cardoso, M. R. (2006). Adolescência: ato e atualidade. Mal-estar e Subjetividade, 6(1), 15-43.

Silva, J. M. (2007). Depois do espetáculo: reflexões sobre a tese 4 de Guy Debord. In C. F. Gutfreind, \& J. M. Silva (Orgs.), Guy Debord antes e depois do espectáculo. Porto Alegre: EDIPUCRS.

Zimerman, D. E. (2003). A psicanálise e a escola. In A. M. S. Bassols (Org.), Saúde mental na escola, uma abordagem interdisciplinar. Porto Alegre: Mediação.

Zimmermann, V. B. (2007). Adolescentes estados-limite: a instituição como aprendiz de historiador. São Paulo: Escuta. 